\title{
Preclinical and Clinical Evaluation of Magnetic-Activated Cell Separation Technology for CTC Isolation in Breast Cancer
}

\author{
Taja Lozar', Tanja Jesenko 1,2, Veronika Kloboves Prevodnik',3, Maja Cemazar',4, \\ Violeta Hosta ${ }^{5}$, Anja Jericevic ${ }^{3}$, Natasa Nolde ${ }^{3}$ and Cvetka Grasic Kuhar ${ }^{1,6 *}$ \\ ${ }^{1}$ Faculty of Medicine, University of Ljubljana, Ljubljana, Slovenia, ${ }^{2}$ Department of Experimental Oncology, Institute \\ of Oncology Ljubljana, Ljubljana, Slovenia, ${ }^{3}$ Department of Cytopathology, Institute of Oncology Ljubljana, Ljubljana, \\ Slovenia, ${ }^{4}$ Faculty of Health Sciences, University of Primorska, Izola, Slovenia, ${ }^{5}$ Department of Dermatovenereology, \\ University Medical Centre Ljubljana, Ljubljana, Slovenia, ${ }^{6}$ Department of Medical Oncology, Institute of Oncology Ljubljana, \\ Ljubljana, Slovenia
}

\section{OPEN ACCESS}

Edited by:

Bernd Kaina,

Johannes Gutenberg University Mainz, Germany

Reviewed by:

Christian Martin Stock, Hannover Medical School, Germany Prashant Trikha,

Nationwide Children's Hospital, United States

*Correspondence:

Cvetka Grasic Kuhar cgrasic@onko-i.si

Specialty section:

This article was submitted to Molecular and Cellular Oncology,

a section of the journal

Frontiers in Oncology

Received: 22 April 2020

Accepted: 25 August 2020 Published: 15 September 2020

Citation:

Lozar T, Jesenko T, Kloboves Prevodnik V, Cemazar M, Hosta V, Jericevic A, Nolde N and Grasic Kuhar C (2020) Preclinical and Clinical Evaluation of Magnetic-Activated Cell Separation Technology for CTC Isolation in Breast Cancer. Front. Oncol. 10:554554. doi: 10.3389/fonc.2020.554554
Circulating tumor cell (CTC) count is an independent prognostic factor in early breast cancer. CTCs can be found in the blood of $20 \%$ of patients prior to neoadjuvant therapy. We aimed to assess the suitability of magnetic-activated cell separation (MACS) technology for isolation and cytological characterization of CTCs. In the preclinical part of the study, cell lines were spiked into buffy coat samples derived from healthy donors, and isolated using MACS. Breast cancer cells with preserved cell morphology were successfully isolated. In the clinical part, blood for CTC isolation was drawn from 44 patients with early and locally advanced breast cancer prior to neoadjuvant chemotherapy. Standard Giemsa, Papanicolaou and pancytokeratin staining was applied. $2.3 \%$ of samples contained cells that meet both the morphological and immunocytochemical criteria for CTC. In 32.6\% of samples, partially degenerated pancytokeratin negative cells with morphological features of tumor cells were observed. In $65.1 \%$ of samples, CTCs were not found. In conclusion, our results demonstrate that morphologically intact tumor cells can be isolated using MACS technology. However, morphologically intact tumor cells were not detected in the clinical part of the study. At present, MACS technology does not appear suitable for use in a clinical cytopathology laboratory.

Keywords: liquid biopsy, magnetic-activated cell separation, circulating tumor cells, morphology, breast cancer

\section{INTRODUCTION}

Circulating tumor cells (CTCs) are believed to be an intermediate step in the metastatic cascade. During growth of the primary or metastatic tumor, epithelial tumor cells may leave the tumor site, invade into a blood or lymphatic vessel and circulate in the bloodstream to disseminate throughout the body, potentially becoming the source of cancer metastases $(1,2)$. These cells are known to exhibit distinct antigenic and morphological characteristics, such as high levels of epithelial-mesenchymal plasticity, larger size compared to white blood cells (WBC), larger nuclear/cytoplasmic (N/C) ratio, and distinct nuclear morphology (3-6). Multiple studies have demonstrated CTC count is an independent prognostic factor in various types of cancer, including 
breast cancer (7-12). In metastatic breast cancer, the presence of 5 or more CTCs per $7.5 \mathrm{ml}$ of blood has been associated with a reduction in progression free survival and overall survival, as well as with higher disease progression and mortality (13-21). In patients with early breast cancer, CTCs can be found in the blood of roughly $20 \%$ of patients prior to neoadjuvant therapy (22-26). The presence of CTCs in peripheral blood has been linked to lymph node metastasis and demonstrated significant prognostic impact on disease-free and overall survival (27). In addition, CTC detection shows promise for assessing treatment efficacy in neoadjuvant therapy (28). CTC detection before neoadjuvant setting carries an independent negative prognostic value for a reduced disease-free and overall survival (29), while not being associated with pathologic complete response $(25,30)$. Taken together, this data indicates that breast cancer patients before neoadjuvant setting may represent a population that might benefit most from CTC diagnostics.

Reliable isolation and detection of CTCs remains a diagnostic challenge. The concentration of CTCs from epithelial-derived cancers has been found to be extremely low ( 1 to 10 cells per $\mathrm{ml}$ blood), presumably due to their short half-life in the blood stream and proneness to constant genotypic and phenotypic changes (4-6, 31-33). In recent years, several methods for CTC isolation and detection have been established and these have been described elsewhere (34). To this day, the CellSearch ${ }^{\circledR}$ is the only Food and Drug Administration approved assay to be used as a prognostic tool in the management of breast cancer, prostate cancer and colorectal cancer patients (11,35-38). The CellSearch ${ }^{\circledR}$ along with many other isolation technologies uses magnetic beads covered with anti-epithelial cell adhesion molecule (EpCAM) antibodies for positive selection of tumor cells of epithelial origin. CTC separation and magnetic bead washing is followed by detection based on immunofluorescent cytokeratin (CK), 4,6-diamidino-2-phenylindole (DAPI) and CD45 (common lymphocyte antigen) staining and subject to single cell level semi-automated morphologic analysis. CTCs can be identified as CK and DAPI positive, CD45 negative cells with a diameter larger than $4 \mu \mathrm{m}$ (38). While this strategy has proven to have prognostic value $(11,36,38,39)$, epithelial cell marker dependent criteria have been associated with some degree of underestimation of CTC numbers (40) related to the epithelialmesenchymal transition phenotype (41).

As previously pointed out by Marrinucci et al. (42), a limitation of fluorescence-based methods is that morphological features of isolated CTCs are difficult to evaluate and compare to the results obtained by routine methods used in cytopathology. Moreover, immunocytochemistry (ICC) cannot be used either. ICC is one of the most widely used tools in cancer diagnostics, mostly because of its role in immunophenotypic characterization of tumor cells before more costly molecular methods. The cytopathology laboratory has been proposed as the ideal environment when attempting to implement CTC enumeration into clinical practice. Besides existing infrastructure, the cytopathologists also possess the required expertise for CTC evaluation, such as integrating morphologic, immunophenotypic and molecular data to provide the patient and the referring clinician with a final diagnosis (43).
In this study, a CTC isolation protocol was designed and tested in a pre-clinical and clinical setting. Positive-selection based magnetic-activated cell sorting (MACS) technology using EpCAM conjugated magnetic beads in the magnetic field was used for CTC isolation (72). The technology was previously reported successful in breast cancer CTC enrichment (44). The aim of the study was to assess the suitability of the technology for CTC diagnostics in the routine cytopathology laboratory. The pre-clinical part of the study aimed to determine the method's sensitivity and specificity, and evaluate if the isolation protocol preserves cancer cell morphology. The aim of the clinical part was CTC isolation and subsequent morphological analysis in patients with early breast cancer prior to neoadjuvant chemotherapy.

\section{MATERIALS AND METHODS}

\section{Study Design}

The study was designed as a preclinical evaluation followed by a prospective clinical trial, and was conducted at the Institute of Oncology Ljubljana, Slovenia. As part of the preclinical evaluation, buffy coat (BC) from healthy donors was spiked with cultured breast cancer cells. The isolation of cancer cells, Giemsa, Papanicolaou and ICC staining, and subsequent microscopical evaluation with recovery rate calculation, were performed at the Department of Cytopathology. To determine the specificity of the isolation protocol, lung fibroblasts were also spiked into $\mathrm{BC}$, which was followed by isolation and an evaluation of the enriched fraction.

In the clinical part of the study, breast cancer patients diagnosed with clinically lymph node-positive disease and/or tumor with a diameter larger than $2 \mathrm{~cm}$ were included in the study. Other inclusion criteria were: age 18 years or older, cytologically confirmed breast cancer, scheduled to receive neoadjuvant chemotherapy, and patient has not yet had core needle biopsy. Data on patient and tumor characteristics and pathological response following neoadjuvant chemotherapy were collected from patient charts. Pathological response was evaluated in tumor and lymph nodes after neoadjuvant chemotherapy. Pathological complete response ( $\mathrm{PCR}$ ) in the tumor was defined as absence of invasive carcinoma in the breast after neoadjuvant chemotherapy. pCR in lymph nodes was defined as absence of invasive carcinoma in the lymph nodes after neoadjuvant chemotherapy. The patients' complete blood counts were examined for the presence of immature erythro-myeloid progenitor cells.

\section{Ethics Statement}

The study was reviewed and approved by the National Medical Ethics Committee at the Slovenian Ministry of Health (ref. nr. 0120-133/2017-2 and 0120-150-2019/4) and was conducted in accordance with the Declaration of Helsinki. All enrolled patients signed an informed consent form.

\section{Blood Samples}

In the preclinical part of the study, BC from the blood of anonymous healthy donors was obtained from the Blood 
Transfusion Centre of Slovenia. BC samples were then diluted using a separation buffer [MACS BSA Stock Solution and autoMACS Rinsing Solution, 1:20, Ph 7.2 phosphate buffer solution (PBS), $0.5 \%$ bovine serum albumin (BSA), $2 \mathrm{mM}$ ethylenediaminetetraacetic acid (EDTA)]. Reference values for WBC content in $\mathrm{BC}$ solutions were obtained from the literature (45) and a dilution coefficient required to achieve a leukocyte/ml concentration in line with reference values for whole blood samples (46) was calculated (1:5).

In the clinical part of the study, patients donated an additional whole peripheral blood sample $(10 \mathrm{ml})$ during a regular blood draw prior to core-needle biopsy. The study sample for CTC isolation was collected last during routine laboratory blood testing to avoid any contamination with skin epithelial cells during needle insertion. The sample was stored in an EDTAcontaining collection tube and processed within $1 \mathrm{~h}$.

\section{Cell Culture and Processing}

Human epithelial breast cancer cell line MCF7 (ATCC ${ }^{\circledR}$ HTB$22^{\mathrm{TM}}$, ATCC, Manassas, United States) and human mesenchymal fibroblast cell line Wi-38 (ATCC $^{\circledR}$ CCL75 $^{\text {TM }}$, ATCC) were purchased directly from ATCC. The cells were propagated in culture using the AMEM medium (Gibco, Thermo Fisher Scientific, Waltham, MA, United States) with 5\% bovine serum, glutamine (10 Mm, Gibco), crystacillin (100 U/ml; Pliva d.d., Zagreb, Croatia) and gentamicin (50 $\mu \mathrm{g} / \mathrm{ml}$; Krka d.d., Novo mesto, Slovenia). The cells were cultured in a $5 \% \mathrm{CO}_{2}$ humidified incubator at $37^{\circ} \mathrm{C}$. The cells were grown as a monolayer until they reached at least $80 \%$ confluence. Afterward, the medium was removed, the cells were first washed with PBS and afterward detached from the surface with $0.25 \%$ trypsin/EDTA in Hank's buffer (Gibco). After detachment, the cells were collected, counted, and a cell suspension with appropriate cell density was prepared. The cultured cells (100 or 1000 cells) were spiked into $10 \mathrm{ml}$ of diluted $\mathrm{BC}$ and processed within $1 \mathrm{~h}$ identically to the patients' whole blood specimens. Altogether, 14 BC samples were spiked with MCF7 cells and eight samples were spiked with Wi-38 cells.

\section{Isolation Protocol}

A positive selection-based MACS technology was used (Miltenyi Biotec, Bergisch Gladbach, Germany) following the manufacturer's instructions. The sample was first filtered through a $30 \mu \mathrm{m}$ pre-separation filter (Miltenyi Biotec). The sample was then incubated with anti-EpCAM magnetic beads (StraightFrom ${ }^{\circledR}$ Whole Blood CD326 (EpCAM) MicroBeads, Miltenyi Biotec, $50 \mu \mathrm{l} / \mathrm{ml}$ blood, $30 \mathrm{~min}, 2-8^{\circ} \mathrm{C}$ ) for magnetic labeling, followed by centrifugation (445 rpm, $10 \mathrm{~min}$ ) and resuspension of the cell fraction with a separation buffer. Magnetic separation was performed using a column containing a matrix composed of ferromagnetic spheres (Whole Blood Columns, Miltenyi Biotec) placed in a separator (QuadroMACS Separator, Miltenyi Biotec). This was followed by the elution step (Whole Blood Column Elution Buffer, Miltenyi Biotec, $5 \mathrm{ml}$ ), yielding an enriched, positively selected fraction. All collection tubes were extensively washed with separation buffer throughout the procedure in order to avoid any potential cell loss.

\section{Staining and Cytopathological Evaluation}

Two slides for microscopical examination (cytospins) were prepared from each isolated fraction by a cytocentrifuge (Thermo Scientific Shandon Cytospin ${ }^{\circledR} 4$ Cytocentrifuge, Waltham, MA, United States) at $1000 \mathrm{rpm}$ for $4 \mathrm{~min}$ at room temperature. One cytospin was air dried at room temperature for a minimum of $30 \mathrm{~min}$ and stained with Lopez Cordosa Giemsa (47). The second cytospin was fixed (Delunay, $30 \mathrm{~min}$ ) and stained with Papanicolaou (PAP) using an automated stainer Leica Multistainer ST5020 (Leica Microsystems, Buffalo Grove, IL, United States). The stained cytospins were then screened by a cytopathologist. Morphological features, such as cell size, amount and quality of cytoplasm, cytoplasmic inclusions, the size of the nucleus and nucleolus, nuclear/cytoplasmic (N/C) ratio, quality of the chromatin and nuclear membrane irregularities were examined. If cells with morphological features in favor of CTC were observed, the PAP stained cytospin was ICC stained with anti CK monoclonal antibody (CK AE1/AE3, ref. nr. M3515, dilution 1:500, Dako, Agilent, Santa Clara, CA, United States). If morphological analysis was inconclusive, additional staining for CD45 (LCA, clone 2B11 + PD7/26, ref. nr. M0701, dilution 1:1000, Dako) was performed on previously CK stained slide to exclude the hematopoietic origin of the cells in question. In slides derived from BC samples spiked with fibroblasts, vimentin expression was ICC determined (clone V9, ref. nr. M0725, dilution 1:4000, Dako). All ICC staining was performed on BenchMark ULTRA imunohistochemical stainer (Ventana, Roche Diagnostics, Oro Valley, AZ, United States) following the manufacturer's instructions.

Cytospins that contained cells with morphological features in favor of CTC were documented and sent for an independent review to three additional cytopathologists. Based on their consensus, the slides were labeled as: (1) CTC positive (canonical), if malignant morphological features as well as $\mathrm{CK}$ positivity were observed in at least one cell, (2) Non-canonical CTCs, if malignant morphological features were observed in at least one cell, but there was no CK expression, and (3) CTC negative, if there were no malignant morphological features suggestive of tumor cells and no CK expression.

\section{Statistical Analysis}

The patient's categorical characteristics were presented as frequencies and proportions. Age was presented as median and range. Pearson's chi-square test was used for statistical comparisons; a $p$-value of $\leq 0.05$ was considered statistically significant. All statistical analysis was performed using SPSS v.24.0 (IBM Corp., Armonk, NY, United States).

\section{RESULTS}

\section{Isolation Sensitivity and Specificity}

The results of sensitivity and specificity analysis are presented in Table 1. To evaluate the method's sensitivity, 14 BC samples were spiked with Michigan Cancer Foundation 7 (MCF7) cells and examined before and after the MACS isolation procedure. Seven BC samples were spiked with 1000 MCF7 cells, and 7 samples 
TABLE 1 | Sensitivity and specificity analysis.

\begin{tabular}{lccc}
\hline Spiked cells (N) & $\begin{array}{c}\text { Experiments } \\
\text { (N) }\end{array}$ & $\begin{array}{c}\text { Recovery } \\
\text { rate (\%) }\end{array}$ & $\begin{array}{c}\mathbf{9 5 \%} \text { confidence } \\
\text { interval }\end{array}$ \\
\hline MCF7 & 7 & & \\
1000 & 7 & 34.3 & $33.2-35.4$ \\
100 & & 28.1 & $24.8-31.6$ \\
Wi-38 & 4 & 0 & - \\
1000 & 4 & 0 & - \\
100 & 4 & & \\
\hline
\end{tabular}

Spiked Michigan Cancer Foundation 7 (MCF7) cells were used to determine the sensitivity of the method. Spiked fibroblasts (Wi-38) were used to determine the specificity of the method.

with 100 MCF7 cells. The recovery rate for 1000 spiked MCF7 cells was 34.31 (95\% CI 33.20-35.44) and 28.14 (95\% CI 24.8431.63) for 100 spiked MCF7 cells. The sensitivity of our isolation protocol was $34 \%$ (95\% CI $32.7-34.82 \%$ ).

To evaluate the specificity of the method, 8 BC samples were spiked with $\mathrm{Wi}-38$ fibroblasts and examined before (Figures 1A,B) and after the MACS isolation procedure (Figure 1C). Four samples were spiked with 100 cells, and four samples were spiked with 1000 cells. No fibroblasts were observed in samples undergoing MACS isolation (Figure 1C). The calculated specificity was 100\% (95\% CI $99.92-100.00 \%)$ (Table 1), since no fibroblasts were observed in samples undergoing MACS isolation (Figure 1C).

\section{Preservation of Morphology of Cultured Tumor Cells}

The isolated MCF7 cells in 14 BC samples were morphologically well preserved and resembled MCF7 cells that had not undergone MACS isolation procedure (Figures $2 \mathbf{A}, \mathbf{B}$ ). The isolated cells were very large compared to WBC, with high N/C ratios and scant to moderate amounts of pale basophilic, vacuolated cytoplasm with cell membrane irregularities and cytoplasmic blebs (Figure 2B). The nuclei were oval, hyperchromatic and pleomorphic. In some cells, nucleoli were visible (Figure 2B). The cells had intact cell membrane and were not damaged or apoptotic. Based on the morphology of isolated MCF-7 cells, we believe the cells are viable after isolation using the MACS technology. Substantial amounts of white blood cells (WBC) and platelets were observed in the background after isolation

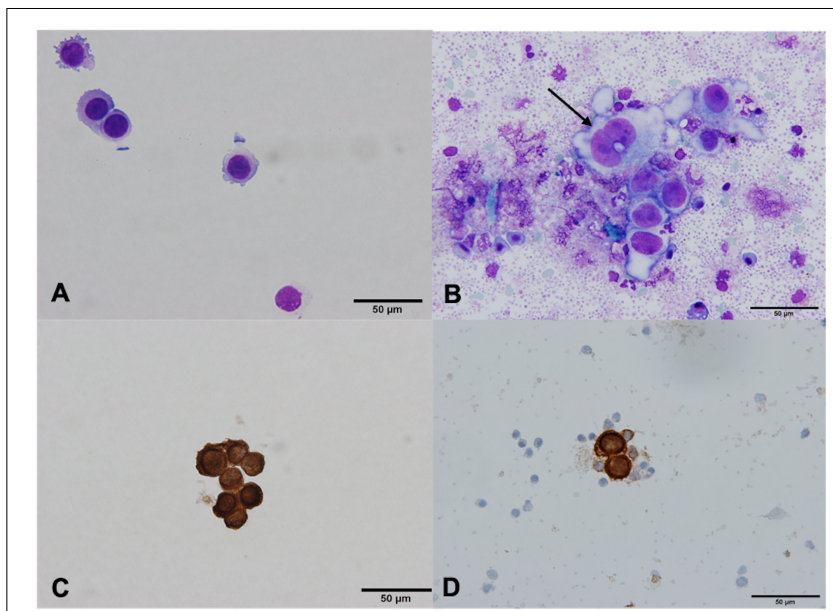

FIGURE 2 | MCF7 cells before and after isolation using MACS technology, $\times 60$. (A) Giemsa stain, before isolation. (B) Giemsa stain, after isolation. MCF7 cells vary in size and shape, and have prominent nucleoli (arrow). Bare nuclei and partially degenerated/apoptotic white blood cells (WBC) and red blood cells (RBC) are in the background. (C) Positive cytokeratin (CK) stain, before isolation. (D) Positive CK stain, after isolation. MCF7 cells are clearly CK positive, surrounded by CK negative WBC and RBC.

(Figure 2B). In MCF7 cells, CK staining was positive in all examined samples (Figures 2C,D).

\section{Prevalence and Morphology of CTCs in Early Breast Cancer}

The characteristics of 43 out of the 44 patients included in the clinical part of the study are summarized in Table 2 . The sample of one patient had to be excluded from the analysis since more than $1 \mathrm{~h}$ had passed between the blood draw and isolation.

In one patient $(2.3 \%)$, the cytospin contained cells that meet the morphological and immunocytochemical criteria for CTC identification (CTC positive, Figures $3 \mathbf{A}, \mathbf{B}$ ). These canonical CTCs were larger than the surrounding WBC, roughly 3-4 times the size of a mature lymphocyte. The cells were oval in shape with scant eosinophilic cytoplasm, a high N/C ratio, and rounded nuclei with dispersed chromatin. The nucleoli were not visible (Figure 3A). ICC staining for CK was positive (Figure 3B).

In $28(65.1 \%)$ patients, no CTCs were detected. However, in $14(32.6 \%)$ patients, the samples contained cells that were

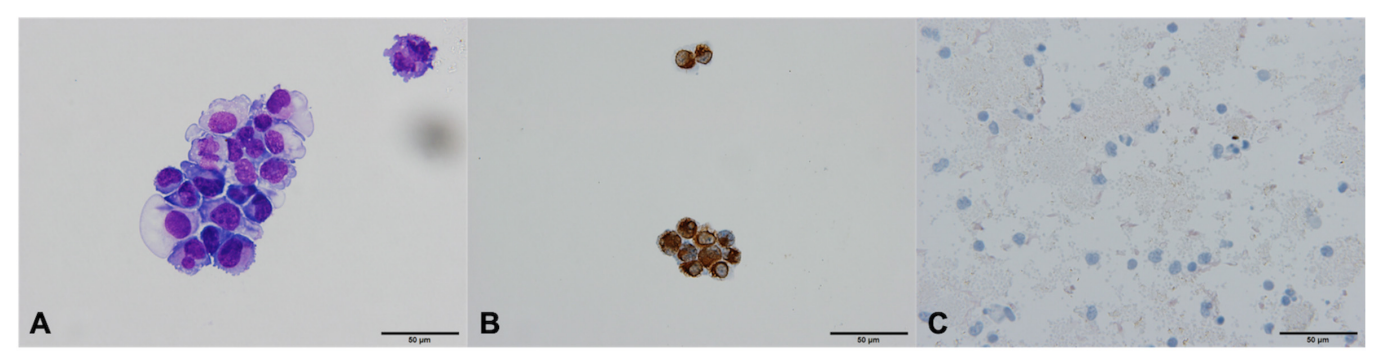

FIGURE 1 | Fibroblasts Wi-38 before and after isolation using MACS technology, x60. (A) Giemsa stain, before isolation. (B) Positive vimentin stain, before isolation. (C) Negative vimentin staining after isolation, demonstrating absence of Wi-38 fibroblasts. 
TABLE 2 | Patient characteristics.

\begin{tabular}{|c|c|}
\hline Characteristic $^{*}$ & $\begin{array}{c}\text { Number of } \\
\text { patients } N=43\end{array}$ \\
\hline Age (years) & $46(26,74)$ \\
\hline \multicolumn{2}{|l|}{ Tumor histology } \\
\hline IDC & $37(86)$ \\
\hline ILC & $5(11.7)$ \\
\hline Mucinous carcinoma & $1(2.3)$ \\
\hline \multicolumn{2}{|l|}{ Tumor grade } \\
\hline$\|$ & $13(30.2)$ \\
\hline III & $30(69.8)$ \\
\hline \multicolumn{2}{|l|}{ Estrogen receptor status } \\
\hline Negative & $14(32.6)$ \\
\hline Positive & $29(67.4)$ \\
\hline \multicolumn{2}{|l|}{ Progesterone receptor status } \\
\hline Negative & $21(48.8)$ \\
\hline Positive & $14(32.6)$ \\
\hline \multicolumn{2}{|l|}{ HER2 receptor status } \\
\hline Negative & $29(67.4)$ \\
\hline Positive & $14(32.6)$ \\
\hline \multicolumn{2}{|l|}{ MIB-1 expression } \\
\hline Negative ( $\leq 10 \%)$ & $5(11.6)$ \\
\hline Positive (>10\%) & $38(88.4)$ \\
\hline \multicolumn{2}{|l|}{ Molecular subtype } \\
\hline Triple negative & $8(18.5)$ \\
\hline HER2 positive & $8(18.5)$ \\
\hline HER2 positive Luminal & $6(14)$ \\
\hline Luminal B-like & $18(42)$ \\
\hline Luminal-A-like & $3(7)$ \\
\hline \multicolumn{2}{|l|}{ Tumor stage } \\
\hline $\mathrm{T} 1$ & $6(14)$ \\
\hline T2 & $23(53.4)$ \\
\hline Т3 & $10(23.3)$ \\
\hline T4 & $4(9.3)$ \\
\hline \multicolumn{2}{|l|}{ Nodal involvement } \\
\hline No & $7(16.3)$ \\
\hline Yes & $36(83.7)$ \\
\hline \multicolumn{2}{|l|}{ Breast cancer stage } \\
\hline$\|$ & $29(67.4)$ \\
\hline III & $12(27.9)$ \\
\hline IV & $2(4.7)$ \\
\hline \multicolumn{2}{|l|}{ Initial treatment } \\
\hline Neoadjuvant chemotherapy & $34(79.1)$ \\
\hline Surgery & $9(20.9)$ \\
\hline \multicolumn{2}{|l|}{ Presence of $\geq 1$ CTC } \\
\hline Negative & $28(65.1)$ \\
\hline Canonical & $1(2.7)$ \\
\hline Non-canonical & $14(32.2)$ \\
\hline \multicolumn{2}{|l|}{ pCR after neoadjuvant chemotherapy } \\
\hline Tumor & $13(30.2)$ \\
\hline Lymph nodes & $17(39.5)$ \\
\hline $\begin{array}{l}\text { Lymph nodes negative before and after } \\
\text { neoadjuvant chemotherapy }\end{array}$ & $5(11.6)$ \\
\hline
\end{tabular}

${ }^{*}$ Presented as number (percentage), except for age, which is presented as median (range). N, number of patients; IDC, invasive ductal carcinoma; IDL, invasive lobular carcinoma; CTC, circulating tumor cells; HER2, human epidermal growth factor receptor 2; pCR, pathological complete response.

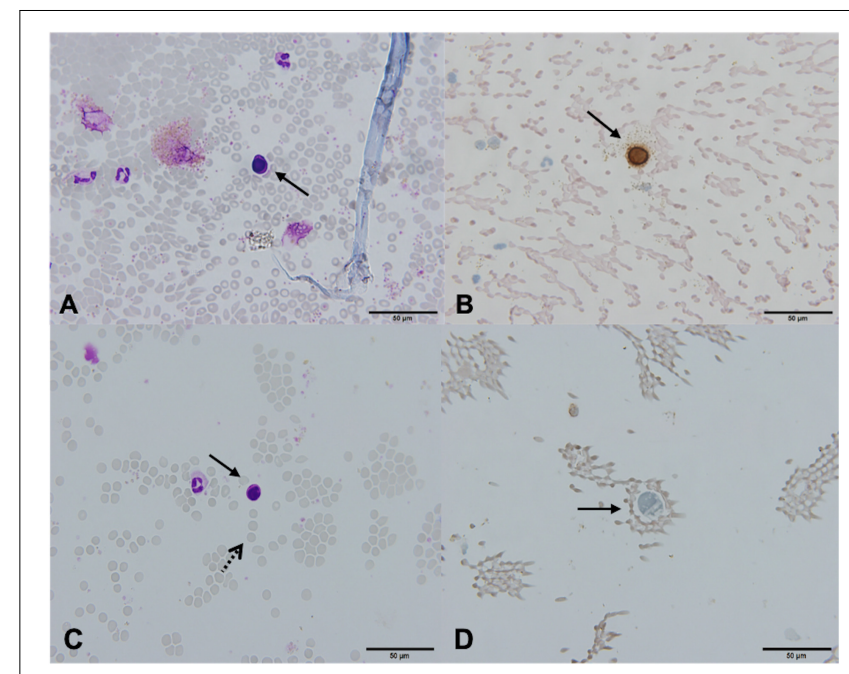

FIGURE 3 | Canonical [Patient 43, (A,B)] and non-canonical [Patient 39, (C,D)] circulating tumor cells (CTCs), ×60. (A) A morphologically preserved cell with features suggestive for CTC, Giemsa stain. (B) Positive immunocytochemical staining for cytokeratin (CK) on a Papanicolaou stained cytospin. (C) A cell resembling a lymphoid cell (arrow). Its diameter is three times the size of the surrounding erythrocytes (dotted arrow). The nucleus is ovoid with altered chromatin structure and high N/C ratio. Giemsa stain.

(D) Cells exhibiting negative staining for CK and CD45 (arrow).

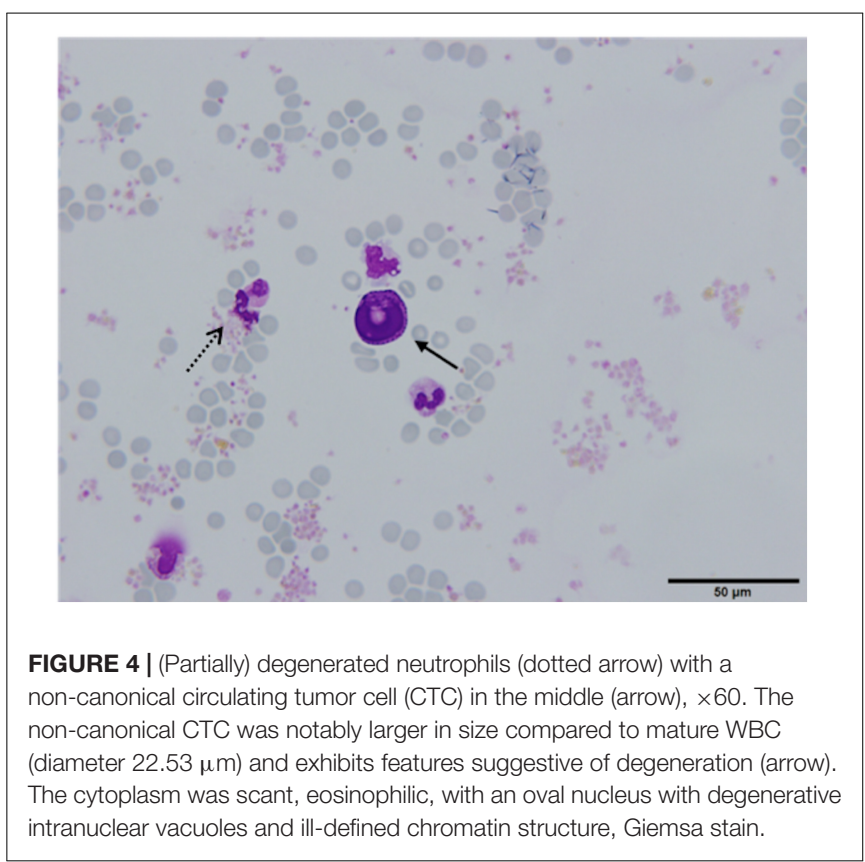

partially degenerated, CK and CD45 negative, but showed morphological features of tumor cells (non-canonical CTCs, Figures 3C,D, 4). We failed to find immature WBC in the complete and differential blood counts of these patients, which could resemble non-canonical CTCs. Furthermore, these noncanonical CTCs did not resemble the surrounding mature WBC. Their morphological features were: scant eosinophilic cytoplasm with vacuoles and eosinophilic inclusions, large nuclei, high N/C 


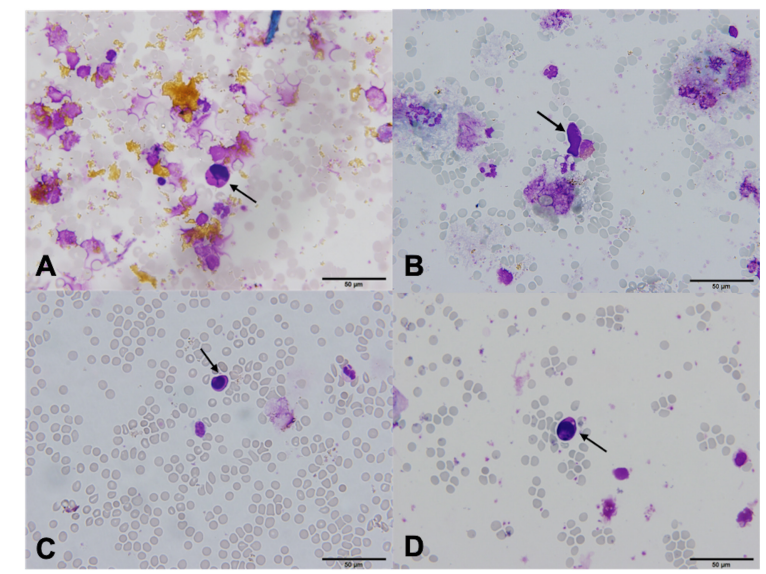

FIGURE 5 | (A-D) Non-canonical circulating tumor cells (CTCs), ×60. Cells with scant eosinophilic cytoplasm, an increased nuclear/cytoplasmic ratio and degenerated nuclei with loss of chromatin structure, Giemsa stain [(A,C,D), arrows]. Single bare nuclei were also observed [(B), arrow]. Yellow granular material was observed in the background of some samples (A).

ratio, and irregular nuclear contours with loss of chromatin structure (Figures 3C,D). WBC, erythrocytes and thrombocytes were observed in the background of all slides after CTC isolation (Figures 4, 5). Bare oval nuclei were also observed (Figure 5B).

\section{Correlation With Tumor Characteristics and Pathological Response}

Circulating tumor cells (canonical and non-canonical) were more often detected in patients undergoing neoadjuvant treatment than surgery ( $41 \%$ vs. $11 \% ; p=0.092$ ). CTCs were detected more often in HER2 positive patients than in HER2 negative patients (50\% vs. 28\%), but this correlation was not statistically significant (Pearson's Hi-square $p=0.148$ ). There was no correlation between age, histology, grade, hormone receptor status, tumor stage, nodal involvement and the presence of CTCs. In 34 patients treated with neoadjuvant chemotherapy, pCR in the breast was achieved in $35 \%$ of CTC positive and in and $40 \%$ of CTC negative samples. In addition, pCR in the lymph nodes was observed in $50 \%$ of CTC positive and CTC negative samples. The presence of CTCs after neoadjuvant chemotherapy was not evaluated.

\section{DISCUSSION}

This study aimed to evaluate the feasibility of the MACS technology for CTC isolation and subsequent cytopathological examination in the routine cytopathological laboratory setting in early breast cancer. The present study is one of the few published studies on the morphology of breast cancer CTCs. It is also one of the few published studies using standard cytopathological techniques for CTC preparation and morphological analysis using light microscopy. The results of this study show that MACS technology preserves the morphology of breast cancer cells from MCF7 cell line, however, this was not observed in CTCs from breast cancer patients. Based on the findings of this study, we believe isolation with MACS technology followed by preparation of standard cytological slides is at present not yet suitable for routine CTC diagnostics in early breast cancer patients.

In clinical trials looking at the performance of CTC isolation methods by spiking cultured tumor cells to whole blood or peripheral blood mononuclear cell suspensions, the preservation of morphology was usually examined using fluorescent microscopy, assessing basic features, such as cell size and $\mathrm{N} / \mathrm{C}$ ratio (3). In the present study, standard light microscopy was used for such examination. The MCF7 cell line was chosen as it is canonical for breast cancer and the most commonly used breast cancer cell line in the literature $(48,49)$, and because our cytopathological laboratory has vast experience with its preparation and light microscopy examination.

The sensitivity of our method as investigated in the preclinical part of the study was found to be lower as previously reported. The recovery rates for positive selection-based isolation methods obtained by spiking cultured breast cancer cells into whole peripheral blood range from 60 to $100 \%(50-52)$. One of the first studies evaluating the performance of immunomagnetic separation using breast cancer cell lines and spiking 1000, 100, and 10 cells found a 75\% recovery rate, which is higher than the recovery rate reported in the present study (34\%) (53). Although extensive washing to prevent potential cell loss was applied, the non-automated handling of samples in our protocol may have resulted in significant cell loss. Furthermore, the manufacturer's protocol is optimized for whole blood samples, therefore the lower sensitivity could also be attributed to the use of diluted BC samples in preclinical part of this study. Unfortunately, we did not plan to obtain whole blood samples from healthy volunteers.

The main challenge we faced in the course of this study was the identification of cells that exhibited morphological features of malignancy while staining negative for CK. The criteria that were used to label the study samples were based on the presence of atypical morphology and CK positivity, similar to the criteria used by Tsutsuyama et al. (54). We identified one $(2.3 \%)$ sample that could be labeled positive based on both criteria, and $65.1 \%$ of samples that were labeled negative. Cells meeting only the morphological criteria were found in $32.6 \%$ of samples. We hypothesized about the origins of these cells. Firstly, they could belong to the erythro-myeloid progenitor cells in the blood of these patients. To rule out this possibility, complete and differential blood counts from a blood sample obtained on the same day as the study sample were examined. No immature erythro-myeloid progenitor cells were identified in any of the samples. Consequently, we hypothesize the observed cells exhibiting malignant features in study samples were in fact degenerated epithelial tumor cells. Our preclinical experiments also showed high isolation specificity, since no spiked lung fibroblasts were observed in the BC samples that underwent the isolation procedure. Based on these observations, the cells in question were labeled non-canonical CTCs.

Although the non-canonical CTCs exhibited morphological features of malignancy, they were severely degenerated (bare, oval nuclei, degenerative intracytoplasmic and intranuclear vacuoles, and nuclear fragmentation) and did not stain for CK. The observed poor preservation of CTCs in patients' 
samples could be due to several possible reasons. CTCs could be damaged by shear stress while still circulating in the blood stream, or they could be circulating apoptotic cells. Additionally, CTCs appear to be more sensitive and fragile compared to cultured cells and, therefore, could be damaged more during the isolation procedure. Moreover, the morphology of isolated tumor cells further changed during cytospin preparation due to the centrifuge force used to transfer the cells to the slides. Such observations have also been reported in a Japanese study using a filtration device and the centrifugation method for cell transfer (54). The authors similarly assumed the centrifugation may have influenced cell morphology of isolated cells in their study.

The morphological characteristics of our CTCs, labeled as non-canonical CTCs, are in line with reported characteristics of CTCs in metastatic breast cancer, lung adenocarcinoma, prostate and colon cancer $(42,55-57)$. Similar to our study, CTCs with nuclear and cytoplasmic fragmentation and irregularities were observed in a study on the morphology of colon cancer CTCs (56). In CTCs from patients with lung adenocarcinoma, nuclear membrane irregularities and chromatin variation ranging from dense to dispersed chromatin with prominent nucleoli were also observed (55). A study by Marinucci et al. investigating the morphologic variation of CTCs in widely metastatic breast cancer is to the best of our knowledge the only study investigating the morphology of breast cancer CTCs. In this study, an immunofluorescent protocol targeting $\mathrm{CK}$ was used for identification and subsequent Wright-Giemsa staining and light microscopy analysis was performed on $\mathrm{CK}$ positive subset (42). In their cohort of CK positive cells, morphological analysis of Giemsa stained slides showed high degree of pleomorphism and several distinct CTC populations. Most notably, a large proportion (23\%) of the isolated cells were larger than the surrounding WBCs, had high N/C ratio, a scant rim of amphophilic to eosinophilic cytoplasm and oval to lobulated nuclear contours. CTCs exhibiting early and late apoptotic changes making up over a half of the whole CTC population were also observed. These features are indeed in line with morphological findings observed in our study. Early apoptotic changes, such as condensation and shrinkage of nuclear material with loss of nuclear detail and formation of cytoplasmic inclusions, as well as late apoptotic changes, such as nuclear fragmentation, were observed in the entire population of cells that were labeled as non-canonical CTCs in our study. We hypothesize the above described apoptotic changes could be correlated to the loss of antigen characteristics and therefore the binding sites for ICC markers, however, all of the abovementioned studies observed such morphological changes in CK positive CTCs, indicating these changes did not affect the ICC staining process $(42,55,56)$.

By performing complementary morphological evaluation in the process of CTC identification, false positive staining of hematopoietic cells due to unspecific binding of antibodies can be avoided (58). However, the utility of such evaluation remains limited because of various isolation methodologies, and their effects on the morphology of isolated cells (42). Another limitation of this approach is the fact that, in contrast to detailed morphological descriptions of primary or secondary tumors in histology and cytopathology, there is scant literature on the morphological features of CTCs and also no widely established morphologic criteria for the identification of CTCs during their travel through the bloodstream (55). As a result, most cytopathologists rely on their knowledge of tumor cell morphology observed in different cytological samples, such as fine needle aspirates, pleural effusions, ascites, bone marrow, etc. They may also rely on criteria used for diagnosing minimal residual disease. A list of objective criteria for the evaluation of minimal residual disease in bone marrow based on morphological analysis and ICC staining was published over a decade ago (59). A few years later, a classification by Fehm et al., integrating morphology, immunophenotyping and genotyping using fluorescent in situ hybridization was introduced (3). Criteria for morphological evaluation used in the present study, such as cell size larger than that of WBC, high N/C ratio, and irregular nuclear contours, were adopted from this classification (3). Based on these morphological criteria, only one patient sample contained cells that could unambiguously be classified as CTCs. An additional 35\% of patient samples contained degenerated cells exhibiting morphological features of tumor cells, i.e., non-canonical CTC. However, based on the existing literature, the morphological criterion alone is not sufficient for definitive CTC identification. To conclude, the non-canonical CTC population observed in our study exhibits characteristics of malignant cells, however, this could not be confirmed with the available identification methods.

The main limitation of this study was the lack of an additional identification protocol that could confirm the cells labeled as non-canonical CTCs, such as genomic or transcriptomic analysis. In addition, flow cytometry could be considered for CTC isolation. Namely, fluorescence-activated cell sorting (FACS) enables simultaneous determination of multiple antigens, which allows sorting of CTCs for further analysis of different CTC populations. Similar to the MACS method, FACS also requires downstream morphological, immunophenotypical and molecular studies for CTC characterization.

Another limitation of the present study was that the viability of isolated cells was not evaluated. This could be performed using trypan blue staining. However, we believe this would not have been successful. Firstly, the number of isolated CTCs was too low. Secondly, we suspect that the morphological differentiation between suspected CTCs and WBCs would not be reliable using trypan blue staining. However, based on the morphology of MCF7 cells on samples stained with Giemsa and PAP, we believe the isolated cells retain viability after MACS isolation.

Furthermore, this study was performed on a patient cohort with early breast cancer. Although proven to be a prognostic factor, CTCs can only be found in about $20 \%$ of this patient population $(10,27,60-62)$. In contrast, between 50 and $70 \%$ of metastatic breast cancer patients have detectable CTCs $(38,63)$. The low numbers of CTCs found in our study could be explained by the high proportion of patients with low stage tumors and low disease stage. Over a half of the patients included in this study had stage II disease, indicating low systemic disease burden. With this in mind, future evaluations of clinical suitability of CTC isolation method should be conducted in a patient cohort with 
more advanced disease stage, such as inflammatory or metastatic breast cancer, where higher CTC prevalence is expected.

Our study found no clinicopathological correlations with the presence of canonical or non-canonical CTCs before neoadjuvant setting, and no impact of detected CTCs on pCR. Published literature has shown correlations with tumor size $(23,64)$, tumor stage, and molecular classification (64). Until recently, no association between CTC detection prior to neoadjuvant therapy and pathological response in early breast cancer has been shown $(23,29)$. Recent evidence suggests conversion from CTC positive to CTC negative state after neoadjuvant therapy may be associated with some degree of pathological response (64). As this was a preliminary study in a small patient cohort, no extended protocol was in place to investigate prognostic relevance or monitor CTC dynamics longitudinally to make our data comparable to published literature. Investigating the method's feasibility and CTC prevalence were our primary end points, and because of low numbers of CTCs and observed degeneration, we feel the MACS isolation method is not sensitive or robust enough to be used for longitudinal monitoring.

At the time of designing this preliminary study, we adapted a commercially available method using a widely established epithelial selection marker. However, by only using epithelial cell surface marker based positive-selection and identification, a potentially more aggressive CTC population that has lost its epithelial markers and gained mesenchymal, can be missed $(65,66)$. High levels of phenotypic heterogeneity among CTCs has been reported $(57,67)$, and while most current CTC detection methods only target EpCAM and/or CK to enrich epithelial CTCs, they may fail to recognize other CTC phenotypes that lack expression of these markers. Since the present study was conducted, increased isolation yields have been shown using an antibody against the mesenchymal marker $\mathrm{N}$-cadherin (68), and using an enrichment strategy combining different antibodies specific for surface proteins and extracellular matrix (69). Unfortunately, no commercially available isolation method combining epithelial and mesenchymal markers was available at the time of the present study. An expanded panel of antibodies specific for epithelial as well as mesenchymal markers should be considered when designing future studies to potentially improve the yield of the proposed isolation protocol. As mentioned, FACS is a method that would allow simultaneous isolation and sorting of different populations of CTCs.

An additional limitation of the MACS technology is its feasibility in clinical practice, mostly due to the duration of the isolation process, as it has been previously noted (70, 71). Together with time required for cytospin preparation and staining, the total processing time can extend to several hours. Moreover, constant supervision is required since most of the procedures are not automated. The implementation of the proposed method into clinical practice would, despite existing infrastructure and the ease of use of the technology itself, require organizational changes, namely in terms of requiring more personnel. Considering CTC analysis has not yet been incorporated into clinical practice guidelines, and its utility despite many other potential applications remains mostly prognostic, the proposed isolation technology does not appear to be sufficiently cost-effective.

\section{CONCLUSION}

The non-invasiveness of the liquid biopsy compared to other diagnostic methods for tumor tissue analysis has sparked great interest for its implementation in clinical practice. The main limitations in the development of isolation technologies are lengthy processing times and low sensitivity. However, in the clinical setting, preservation of morphology by the isolation procedure is of particular interest, as it may enable cytopathological evaluation with existing resources. Due to the morphological degeneration of isolated breast cancer CTCs, which could be due either to apoptotic cell death, the isolation process, or to sheer forces in the bloodstream, we believe the MACS technology followed by preparation of standard cytological slides is not suitable for use in a clinical cytopathology laboratory for isolation of CTCs from the blood of early or locally advanced breast cancer patients. Nevertheless, considering the high isolation specificity and the fact that the MCF7 cells were well preserved following the isolation protocol, the method could well be used for research purposes for enrichment of specific cell types or in studies where cytological samples are studied.

\section{DATA AVAILABILITY STATEMENT}

The raw data supporting the conclusions of this article will be made available by the authors, without undue reservation.

\section{ETHICS STATEMENT}

The studies involving human participants were reviewed and approved by the National Medical Ethics Committee at the Slovenian Ministry of Health. The patients/participants provided their written informed consent to participate in this study.

\section{AUTHOR CONTRIBUTIONS}

CGK, TJ, VKP, and MC: conceptualization. CGK and TJ: methodology. TL, TJ, VH, AJ, NN, and VKP: analysis and investigation. CGK: resources. TL: writing - original draft preparation. TJ, CGK, MC, VKP, and NN: writing - review and editing. All authors have read and agreed to the published version of the manuscript.

\section{FUNDING}

This research was funded by the Slovenian Research Agency (Program Nos. P3-0003, P3-0289, and P3-0321).

\section{ACKNOWLEDGMENTS}

The authors would like to thank Klara Gersak, MD, for her contribution in carrying out this study. The authors would also like to thank Ulrika Klopcic, MD, Ph.D., for her help with evaluating cytological samples. 


\section{REFERENCES}

1. Tarin D. Investigations of the mechanisms of metastatic spread of naturally occurring neoplasms. Cancer Metastasis Rev. (1982) 1:215-25. doi: 10.1007/ BF00046828

2. Diamantopoulou Z, Castro-Giner F, Aceto N. Circulating tumor cells: ready for translation? J Exp Med. (2020) 217:e20200356. doi: 10.1084/jem.20200356

3. Fehm T, Solomayer EF, Meng S, Tucker T, Lane N, Wang J, et al. Methods for isolating circulating epithelial cells and criteria for their classification as carcinoma cells. Cytotherapy. (2005) 7:171-85. doi: 10.1080/ 14653240510027082

4. Jolly MK, Boareto M, Huang B, Jia D, Lu M, Onuchic JN, et al. Implications of the hybrid epithelial/mesenchymal phenotype in metastasis. Front Oncol. (2015) 5:155. doi: 10.3389/fonc.2015.00155

5. Lecharpentier A, Vielh P, Perez-Moreno P, Planchard D, Soria JC, Farace F. Detection of circulating tumour cells with a hybrid (epithelial/ mesenchymal) phenotype in patients with metastatic non-small cell lung cancer. Br J Cancer. (2011) 105:1338-41. doi: 10.1038/bjc.2011.405

6. Armstrong AJ, Marengo MS, Oltean S, Kemeny G, Bitting RL, Turnbull JD, et al. Circulating tumor cells from patients with advanced prostate and breast cancer display both epithelial and mesenchymal markers. Mol Cancer Res. (2011) 9:997-1007. doi: 10.1158/1541-7786.MCR-10-0490

7. Huang X, Gao P, Song Y, Sun J, Chen X, Zhao J, et al. Meta-analysis of the prognostic value of circulating tumor cells detected with the CellSearch System in colorectal cancer. BMC Cancer. (2015) 15:202. doi: 10.1186/s12885-0151218-9

8. Vlaeminck-Guillem V. When prostate cancer circulates in the bloodstream. Diagnostics. (2015) 5:428-74. doi: 10.3390/diagnostics5040428

9. Krebs MG, Sloane R, Priest L, Lancashire L, Hou JM, Greystoke A, et al Evaluation and prognostic significance of circulating tumor cells in patients with non-small-cell lung cancer. J Clin Oncol. (2011) 29:1556-63. doi: 10.1200/ JCO.2010.28.7045

10. Janni WJ, Rack B, Terstappen LWMM, Pierga JY, Taran FA, Fehm T, et al. Pooled analysis of the prognostic relevance of circulating tumor cells in primary breast cancer. Clin Cancer Res. (2016) 22:2583-93. doi: 10.1158/10780432.CCR-15- 1603

11. Cohen SJ, Punt CJA, Iannotti N, Saidman BH, Sabbath KD, Gabrail NY, et al. Relationship of circulating tumor cells to tumor response, progression-free survival, and overall survival in patients with metastatic colorectal cancer. $J$ Clin Oncol. (2008) 26:3213-21. doi: 10.1200/JCO.2007.15.8923

12. Bidard FC, Huguet F, Louvet C, Mineur L, Bouché O, Chibaudel B, et al. Circulating tumor cells in locally advanced pancreatic adenocarcinoma: the ancillary CirCe 07 study to the LAP 07 trial. Ann Oncol. (2013) 24:2057-61. doi: 10.1093/annonc/mdt176

13. Zhang L, Riethdorf S, Wu G, Wang T, Yang K, Peng G, et al. Meta-analysis of the prognostic value of circulating tumor cells in breast cancer. Clin Cancer Res. (2012) 18:5701-10. doi: 10.1158/1078-0432.CCR-12-1587

14. Pierga JY, Hajage D, Bachelot T, Delaloge S, Brain E, Campone M, et al. High independent prognostic and predictive value of circulating tumor cells compared with serum tumor markers in a large prospective trial in firstline chemotherapy for metastatic breast cancer patients. Ann Oncol. (2012) 23:618-24. doi: 10.1093/annonc/mdr263

15. Cristofanilli M, Hayes DF, Budd GT, Ellis MJ, Stopeck A, Reuben JM, et al. Circulating tumor cells: a novel prognostic factor for newly diagnosed metastatic breast cancer. J Clin Oncol. (2005) 23:1420-30. doi: 10.1200/JCO. 2005.08.140

16. Dawood S, Broglio K, Valero V, Reuben J, Handy B, Islam R, et al. Circulating tumor cells in metastatic breast cancer: from prognostic stratification to modification of the staging system? Cancer. (2008) 113:2422-30. doi: 10.1002/ cncr.23852

17. Hayes DF, Cristofanilli M, Budd GT, Ellis MJ, Stopeck A, Miller MC, et al. Circulating tumor cells at each follow-up time point during therapy of metastatic breast cancer patients predict progression-free and overall survival. Clin Cancer Res. (2006) 12:4218-24. doi: 10.1158/1078-0432.CCR-05-2821

18. Nolé F, Munzone E, Zorzino L, Minchella I, Salvatici M, Botteri E, et al. Variation of circulating tumor cell levels during treatment of metastatic breast cancer: prognostic and therapeutic implications. Ann Oncol. (2008) 19:891-7. doi: 10.1093/annonc/mdm558

19. Paoletti C, Li Y, Muñiz MC, Kidwell KM, Aung K, Thomas DG, et al Significance of circulating tumor cells in metastatic triple-negative breast cancer patients within a randomized, phase II trial: TBCRC 019. Clin Cancer Res. (2015) 21:2771-9. doi: 10.1158/1078-0432.CCR-14-2781

20. Yan WT, Cui X, Chen Q, Li YF, Cui YH, Wang Y, et al. Circulating tumor cell status monitors the treatment responses in breast cancer patients: a meta-analysis. Sci Rep. (2017) 7:43464. doi: 10.1038/srep43464

21. Giuliano M, Giordano A, Jackson S, Hess KR, De Giorgi U, Mego M, et al. Circulating tumor cells as prognostic and predictive markers in metastatic breast cancer patients receiving first-line systemic treatment. Breast Cancer Res. (2011) 13:R67. doi: 10.1186/bcr2907

22. Hall CS, Karhade MG, Bowman Bauldry JB, Valad LM, Kuerer HM, Desnyder SM, et al. Prognostic value of circulating tumor cells identified before surgical resection in nonmetastatic breast cancer patients. J Am Coll Surg. (2016) 223:20-9. doi: 10.1016/j.jamcollsurg.2016.02.021

23. Bidard FC, Michiels S, Riethdorf S, Mueller V, Esserman LJ, Lucci A, et al. Circulating tumor cells in breast cancer patients treated by neoadjuvant chemotherapy: a meta-analysis. J Natl Cancer Inst. (2018) 110:560-7. doi: 10.1093/jnci/djy018

24. Trapp E, Janni W, Schindlbeck C, Jückstock J, Andergassen U, De Gregorio A, et al. Presence of circulating tumor cells in high-risk early breast cancer during follow-up and prognosis. J Natl Cancer Inst. (2019) 111:380-7. doi: 10.1093/jnci/djy152

25. Riethdorf S, Müller V, Zhang L, Rau T, Loibl S, Komor M, et al. Detection and HER2 expression of circulating tumor cells: prospective monitoring in breast cancer patients treated in the neoadjuvant GeparQuattro trial. Clin Cancer Res. (2010) 16:2634-45. doi: 10.1158/1078-0432.CCR-09-2042

26. Jueckstock J, Rack B, Friedl TWP, Scholz C, Steidl J, Trapp E, et al. Detection of circulating tumor cells using manually performed immunocytochemistry (MICC) does not correlate with outcome in patients with early breast cancerresults of the German SUCCESS-A- trial. BMC Cancer. (2016) 16:401. doi: 10.1186/s12885-016-2454-3

27. Rack B, Schindlbeck C, Jückstock J, Andergassen U, Hepp P, Zwingers T, et al. Circulating tumor cells predict survival in early average-to-high risk breast cancer patients. J Natl Cancer Inst. (2014) 106:dju066. doi: 10.1093/jnci/ dju066

28. Riethdorf S, O'Flaherty L, Hille C, Pantel K. Clinical applications of the CellSearch platform in cancer patients. Adv Drug Deliv Rev. (2018) 125:10221. doi: 10.1016/j.addr.2018.01.011

29. Riethdorf S, Müller V, Loibl S, Nekljudova V, Weber K, Huober J, et al. Prognostic impact of circulating tumor cells for breast cancer patients treated in the neoadjuvant "Geparquattro" trial. Clin Cancer Res. (2017) 23:5384-93. doi: 10.1158/1078-0432.CCR-17-0255

30. Pierga JY, Bidard FC, Mathiot C, Brain E, Delaloge S, Giachetti S, et al. Circulating tumor cell detection predicts early metastatic relapse after neoadjuvant chemotherapy in large operable and locally advanced breast cancer in a phase II randomized trial. Clin Cancer Res. (2008) 14:7004-10. doi: 10.1158/1078-0432.CCR-08-0030

31. Micalizzi DS, Maheswaran S, Haber DA. A conduit to metastasis: circulating tumor cell biology. Genes Dev. (2017) 31:1827-40. doi: 10.1101/gad.305805. 117

32. Pantel K, Speicher MR. The biology of circulating tumor cells. Oncogene. (2016) 35:1216-24. doi: 10.1038/onc.2015.192

33. Aceto N, Bardia A, Miyamoto DT, Donaldson MC, Wittner BS, Spencer JA, et al. Circulating tumor cell clusters are oligoclonal precursors of breast cancer metastasis. Cell. (2014) 158:1110-22. doi: 10.1016/j.cell.2014.07.013

34. Agnoletto C, Corrà F, Minotti L, Baldassari F, Crudele F, Cook WJJ, et al. Heterogeneity in circulating tumor cells: the relevance of the stem-cell subset. Cancers (Basel). (2019) 11:483. doi: 10.3390/cancers11040483

35. Allard WJ, Matera J, Miller MC, Repollet M, Connelly MC, Rao C, et al. Tumor cells circulate in the peripheral blood of all major carcinomas but not in healthy subjects or patients with nonmalignant diseases. Clin Cancer Res. (2004) 10:6897-904. doi: 10.1158/1078-0432.CCR-04-0378

36. De Bono JS, Scher HI, Montgomery RB, Parker C, Miller MC, Tissing H, et al. Circulating tumor cells predict survival benefit from treatment in metastatic castration-resistant prostate cancer. Clin Cancer Res. (2008) 14:6302-9. doi: 10.1158/1078-0432.CCR-08-0872

37. Veridex LLC. CellSearch Circulating Tumor Cell Kit (Epithelial) User's Guide. (2019). Available online at: http://documents.cellsearchctc.com/pdf/ e631600001/e631600001_EN.pdf (accessed August 13, 2019).

38. Cristofanilli M, Budd GT, Ellis MJ, Stopeck A, Matera J, Miller MC, et al. Circulating tumor cells, disease progression, and survival in metastatic 
breast cancer. N Engl J Med. (2004) 351:781-91. doi: 10.1056/NEJMoa0 40766

39. Miller MC, Doyle GV, Terstappen LWMM. Significance of circulating tumor cells detected by the cellsearch system in patients with metastatic breast colorectal and prostate cancer. J Oncol. (2010) 2010:1-8. doi: 10.1155/2010/ 617421

40. Park S, Ang RR, Duffy SP, Bazov J, Chi KN, Black PC, et al. Morphological differences between circulating tumor cells from prostate cancer patients and cultured prostate cancer cells. PLoS One. (2014) 9:e85264. doi: 10.1371/ journal.pone.0085264

41. Werner S, Stenzl A, Pantel K, Todenhöfer T. Expression of epithelial mesenchymal transition and cancer stem cell markers in circulating tumor cells. Adv Exp Med Biol. (2017) 994:205-28. doi: 10.1007/978-3-319-55947$6 \_11$

42. Marrinucci D, Bethel K, Bruce RH, Curry DN, Hsieh B, Humphrey M, et al. Case study of the morphologic variation of circulating tumor cells. Hum Pathol. (2007) 38:514-9. doi: 10.1016/j.humpath.2006.08.027

43. Lowe AC, Pignon JC, Carvo I, Drage MG, Constantine NM, Jones N, et al. Young investigator challenge: application of cytologic techniques to circulating tumor cell specimens: detecting activation of the oncogenic transcription factor STAT3. Cancer Cytopathol. (2015) 123:696-705. doi: 10. $1002 /$ cncy. 21640

44. Hu XC, Wang Y, Shi DR, Loo TY, Chow LWC. Immunomagnetic tumor cell enrichment is promising in detecting circulating breast cancer cells. Oncology. (2003) 64:160-5. doi: 10.1159/000067776

45. Joint Ukbts Professional Advisory Committee. Granulocyte Therapy (internet). (2019). Available online at: https://www.transfusionguidelines.org/documentlibrary/documents/position-statement-granulocyte-therapy/download-file/ Position\%20Statement\%20on\%20Granulocyte\%20Therapy\%20February\% 202014.pdf (2014) (accessed August 13, 2019).

46. Onkološki inštitut Ljubljana. Oddelek za Laboratorijske Dejavnosti Ljubljana. (2019). Available online at: https://www.onko-i.si/fileadmin/onko/datoteke/ Dejavnosti/10.6.Katalog_preiskav_koncna_ver_7_.pdf (accessed August 13, 2019).

47. Boon ME, Drijver JS. Routine Cytological Staining Techniques. London: Palgrave (1986). doi: 10.1007/978-1-349-18250-3

48. Shen Z, Wu A, Chen X. Current detection technologies for circulating tumor cells. Chem Soc Rev. (2017) 46:2038-56. doi: 10.1039/c6cs00803h

49. Adams DL, Zhu P, Makarova OV, Martin SS, Charpentier M, Chumsri S, et al. The systematic study of circulating tumor cell isolation using lithographic microfilters. RSC Adv. (2014) 4:4334-42. doi: 10.1039/c3ra46839a

50. Racila E, Euhus D, Weiss AJ, Rao C, McConnell J, Terstappen LWMM, et al. Detection and characterization of carcinoma cells in the blood. Proc Natl Acad Sci USA. (1998) 95:4589-94. doi: 10.1073/pnas.95.8.4589

51. Witzig TE, Bossy B, Kimlinger T, Roche PC, Ingle JN, Grant C, et al. Detection of circulating cytokeratin-positive cells in the blood of breast cancer patients using immunomagnetic enrichment and digital microscopy. Clin Cancer Res. (2002) 8:1085-91.

52. Gaforio JJ, Serrano MJ, Sanchez-Rovira P, Sirvent A, Delgado-Rodriguez M, Campos M, et al. Detection of breast cancer cells in the peripheral blood is positively correlated with estrogen-receptor status and predicts for poor prognosis. Int J Cancer. (2003) 107:984-90. doi: 10.1002/ijc.11479

53. Naume B, Borgen E, Beiske K, Herstad TK, Ravnås G, Renolen A, et al. Immunomagnetic techniques for the enrichment and detection of isolated breast carcinoma cells in bone marrow and peripheral blood. J Hematotherapy Stem Cell Res. (1997) 6:103-14. doi: 10.1089/scd.1.1997.6.103

54. Tsutsuyama M, Nakanishi H, Yoshimura M, Oshiro T, Kinoshita T, Komori $\mathrm{K}$, et al. Detection of circulating tumor cells in drainage venous blood from colorectal cancer patients using a new filtration and cytology-based automated platform. PLoS One. (2019) 14:e0212221. doi: 10.1371/journal.pone.0212221

55. Marrinucci D, Bethel $K$, Luttgen M, Bruce RH, Nieva J, Kuhn P. Circulating tumor cells from well-differentiated lung adenocarcinoma retain cytomorphologic features of primary tumor type. Arch Pathol Lab Med. (2009) 133:1468-71. doi: 10.1043/1543-2165-133.9.1468

56. Marrinucci D, Bethel K, Lazar D, Fisher J, Huynh E, Clark P, et al. Cytomorphology of circulating colorectal tumor cells: a small case series. $J$ Oncol. (2010) 2010:1-7. doi: 10.1155/2010/861341

57. McDaniel AS, Ferraldeschi R, Krupa R, Landers M, Graf R, Louw J, et al. Phenotypic diversity of circulating tumour cells in patients with metastatic castration-resistant prostate cancer. BJU Int. (2017) 120:E30-44. doi: 10.1111/ bju. 13631
58. Borgen E, Beiske K, Trachsel S, Nesland JM, Kvalheim G, Herstad TK, et al. Immunocytochemical detection of isolated epithelial cells in bone marrow: non-specific staining and contribution by plasma cells directly reactive to alkaline phosphatase. J Pathol. (1998) 185:427-34. doi: 10.1002/(SICI)10969896(199808) 185:43.0.CO;2-7

59. Borgen E, Naume B, Nesland JM, Kvalheim G, Beiske K, Fodstad O, et al. Standardization of the immunocytochemical detection of cancer cells in BM and blood: I. establishment of objective criteria for the evaluation of immunostained cells: the European ISHAGE working group for standardization of tumor cell detection. Cytotherapy. (1999) 1:377-88. doi: $10.1080 / 0032472031000141283$

60. Lucci A, Hall CS, Lodhi AK, Bhattacharyya A, Anderson AE, Xiao L, et al. Circulating tumour cells in non-metastatic breast cancer: a prospective study. Lancet Oncol. (2012) 13:688-95. doi: 10.1016/S1470-2045(12)70209-7

61. Bidard F-C, Belin L, Delaloge S, Lerebours F, Ngo C, Reyal F, et al. Timedependent prognostic impact of circulating tumor cells detection in nonmetastatic breast cancer: 70-month analysis of the REMAGUS02 study. Int J Breast Cancer. (2013) 2013:1-5. doi: 10.1155/2013/130470

62. Franken B, de Groot MR, Mastboom WJB, Vermes I, van der Palen J, Tibbe AGJ, et al. Circulating tumor cells, disease recurrence and survival in newly diagnosed breast cancer. Breast Cancer Res. (2012) 14:R133. doi: 10.1186/ bcr3333

63. Sarangi S, Mosalpuria K, Higgins MJ, Bardia A. The evolving role of circulating tumor cells in the personalized management of breast cancer: from enumeration to molecular characterization. Curr Breast Cancer Rep. (2014) 6:146-53. doi: 10.1007/s12609-014-0149-9

64. Ni C, Shen Y, Fang Q, Zhang M, Yuan H, Zhang J, et al. Prospective study of the relevance of circulating tumor cell status and neoadjuvant chemotherapy effectiveness in early breast cancer. Cancer Med. (2020) 9:2290-8. doi: 10.1002/ cam4.2876

65. Kalluri R, Weinberg RA. The basics of epithelial-mesenchymal transition. $J$ Clin Invest. (2009) 119:1420-8. doi: 10.1172/JCI39104

66. Scheel C, Weinberg RA. Cancer stem cells and epithelial-mesenchymal transition: concepts and molecular links. Semin Cancer Biol. (2012) 22:396403. doi: 10.1016/j.semcancer.2012.04.001

67. Attard G, Swennenhuis JF, Olmos D, Reid AHM, Vickers E, A'Hern R, et al. Characterization of ERG, AR and PTEN gene status in circulating tumor cells from patients with castration-resistant prostate cancer. Cancer Res. (2009) 69:2912-8. doi: 10.1158/0008-5472.CAN-08-3667

68. Po JW, Roohullah A, Lynch D, DeFazio A, Harrison M, Harnett PR, et al. Improved ovarian cancer EMT-CTC isolation by immunomagnetic targeting of epithelial EpCAM and mesenchymal N-cadherin. J Circ Biomarkers. (2018) 7:1849454418782617. doi: 10.1177/1849454418782617

69. Schneck H, Gierke B, Uppenkamp F, Behrens B, Niederacher D, Stoecklein $\mathrm{NH}$, et al. EpCAM-independent enrichment of circulating tumor cells in metastatic breast cancer. PLoS One. (2015) 10:e0144535. doi: 10.1371/journal. pone. 0144535

70. Faraghat SA, Hoettges KF, Steinbach MK, Van Der Veen DR, Brackenbury WJ, Henslee EA, et al. High-throughput, low-loss, low-cost, and labelfree cell separation using electrophysiology-Activated cell enrichment. Proc Natl Acad Sci USA. (2017) 114:4591-6. doi: 10.1073/pnas.170077 3114

71. Paterlini-Brechot P, Benali NL. Circulating tumor cells (CTC) detection: clinical impact and future directions. Cancer Lett. (2007) 253:180-204. doi: 10.1016/j.canlet.2006.12.014

72. Miltenyi S, Müller W, Weichel W, Radbruch A. High gradient magnetic cell separation with MACS. Cytometry. (1990) 11:231-8. doi: 10.1002/cyto. 990110203

Conflict of Interest: The authors declare that the research was conducted in the absence of any commercial or financial relationships that could be construed as a potential conflict of interest.

Copyright ( 12020 Lozar, Jesenko, Kloboves Prevodnik, Cemazar, Hosta, Jericevic, Nolde and Grasic Kuhar. This is an open-access article distributed under the terms of the Creative Commons Attribution License (CC BY). The use, distribution or reproduction in other forums is permitted, provided the original author(s) and the copyright owner(s) are credited and that the original publication in this journal is cited, in accordance with accepted academic practice. No use, distribution or reproduction is permitted which does not comply with these terms. 